\title{
Superplastic Behavior of a Fine Grained AZ61 Alloy Processed by Large Strain Hot Rolling
}

\author{
M.T. Pérez-Prado, J. A. del Valle ${ }^{1}$, and O.A. Ruano \\ Dept. of Physical Metallurgy, Centro Nacional de Investigaciones Metalúrgicas (CENIM), \\ CSIC, Avda. de Gregorio del Amo, 8, 28040 Madrid, Spain
}

Keywords: AZ61, Mg alloy, large strain hot rolling, superplasticity.

\begin{abstract}
A processing route based on conventional hot rolling has been recently developed to induce significant grain refinement in Mg alloys. The simplicity and rapidity of the processing route as well as the fact that conventional rolling is used, may allow it to be put into practice successfully in industry. This method consists of only two to three rolling passes, each producing a large thickness reduction, and intermediate annealings of 5 minutes duration. The resulting microstructure is mainly formed by very fine grains. Tensile tests at different temperatures and strain rates were performed in order to analyse the mechanical behaviour of the processed AZ61 alloy under different testing conditions. Microstructure and texture evolution during deformation were examined by optical microscopy (OM) and X-ray diffraction, respectively. It is shown that the microstructures developed by large strain hot rolling are capable of exhibiting significant superplastic elongations at moderate to low temperatures. Stress exponents close to 2 were measured during deformation under optimum superplastic conditions. Additionally, grains remained equiaxed and a significant decrease in the texture intensity is observed. This is consistent with the predominance of grain boundary sliding as the main deformation mechanism responsible for superplasticity.
\end{abstract}

\section{Introduction}

Magnesium alloys are attractive materials for the automotive industry due to their excellent specific properties such as low density $\left(1.74 \mathrm{~g} / \mathrm{cm}^{3}\right)$ and high specific strength [1]. Additionally these materials have great potential for low temperature superplasticity (LTS) due to their high diffusion coefficient (the pre-exponential factor for grain boundary diffusion, $\delta \mathrm{D}_{\mathrm{gb}}$, is two orders of magnitude larger than that of aluminum) [2]. LTS offers the possibility of attaining large elongations at moderate temperatures, presumably even at room temperature if a sufficiently small grain size is present. Optimizing LTS in Mg alloys would be specially desirable since, due to their hcp structure, these materials have low room temperature ductility and are therefore difficult to form.

Two microstructural prerequisites are needed in order to obtain an optimum superplastic behavior: a fine grain size [3] and equilibrium grain boundaries [4]. Various grain refinement methods have been proposed for $\mathrm{Mg}$ alloys such as conventional extrusion using large extrusion ratios, powder metallurgy routes or methods based on severe plastic deformation [5]. Conventional thermomechanical ingot processing by hot extrusion has allowed to prepare microstructures with grain sizes finer than $10 \mu \mathrm{m}$. Recently Lin et al. [6,7] have reported grain sizes as small as $0.6 \mu \mathrm{m}$ fabricated using extrusion ratios of 166:1. Powder metallurgy techniques have been successfully applied to obtain $1 \mu \mathrm{m}$ grain sizes [8]. SPD methods such as equal channel angular extrusion (ECAE), in turn, allow engineering of microstructures with submicron or nanocrystalline grain sizes [9]. The present authors have recently developed an alternative processing method for superplastic Mg alloys via large strain hot rolling (LSR). This simple procedure aims to obtain significant grain refinement through a small number of passes with high reduction per pass. It has been shown $[10,11]$ that grain sizes as small as $1-2 \mu \mathrm{m}$ can be obtained after only one to two rolling passes.

\footnotetext{
${ }^{1}$ On leave from Consejo Nacional de Investigaciones Científicas y Técnicas (CONICET), Argentina
} 
However, the final microstructure is not fully homogeneous, since an appreciable fraction of larger grains are also present after processing. Nevertheless, preliminary mechanical property data seemed to show an improved superplastic response in Mg alloys processed via large strain hot rolling [10].

The aim of the present paper is to explore the superplastic behavior of an AZ61 Mg alloy processed by LSR. The underlying rate-controlling deformation mechanisms are also investigated.

\section{Experimental procedure}

The AZ61 alloy studied was received as-extruded in the form of a sheet, $10 \mathrm{~mm}$ in thickness. The main alloying elements in this $\mathrm{Mg}$ based alloy are: $\mathrm{Al}(6 \%)$ and $\mathrm{Zn} \mathrm{(1 \% ).}$

The as-received material was processed for grain refinement via large strain hot rolling as explained in [10]. The processing route consisted on three rolling passes with reductions of 20\%, $35 \%$, and 55\%, respectively. Tensile specimens of $20 \mathrm{~mm}$ gage length and a radius of $3 \mathrm{~mm}$ were machined out of the rolled sheet with the tensile axis parallel to the rolling direction of the final pass. Tensile tests to failure were performed at temperatures within the interval $\left(100^{\circ} \mathrm{C}\right.$ and $\left.400^{\circ} \mathrm{C}\right)$ and at constant crosshead speeds of $10^{-3} \mathrm{~s}^{-1}$ and $10^{-4} \mathrm{~s}^{-1}$. Strain rate change tests were also performed in order to measure the stress exponents and activation energies.

The microstructure of the AZ61 alloy was investigated by optical microscopy (OM). Sample preparation consisted on grinding on $\mathrm{SiC}$ paper with increasingly finer grits, followed by mechanical polishing with $6 \mu \mathrm{m}$ and $1 \mu \mathrm{m}$ diamond paste and final polishing using colloidal silica. The grain structure was revealed by subsequent etching using a solution of ethanol (100 ml), picric acid (5 g), acetic acid (5 ml) and water $(10 \mathrm{ml})$. After chemical etching a residual layer remained in the sample surface that was eliminated by immersion in boiling ethanol.

Texture analysis has proven to be a powerful tool to obtain exhaustive microstructural information [12]. The macrotexture of the AZ61 alloy was measured by the Schulz reflection method in a Siemens diffractometer furnished with a closed eulerian cradle.

\section{Results and discussion}

Figure 1 shows the microstructure of the AZ61 alloy in the as-received condition (Fig. 1a) and after large strain hot rolling at $375^{\circ} \mathrm{C}$ consisting of three passes with reductions of $20 \%$, $35 \%$, and $55 \%$, respectively (Fig. 1b). It can be seen that the original grain size (around $54 \mu \mathrm{m}$ ) is significantly reduced after processing. The resulting microstructure is rather heterogeneous. A small number of large grains of approximately $20 \mu \mathrm{m}$ in diameter are embedded in a matrix of small recrystallized grains of approximately $5 \mu \mathrm{m}$ in diameter. The final average grain size is near $6 \mu \mathrm{m}$. Figure 2 shows the (0002), (10-10), and (11-20) pole figures corresponding to the AZ61 alloy after LSR. A clear basal texture can be observed.

(a)

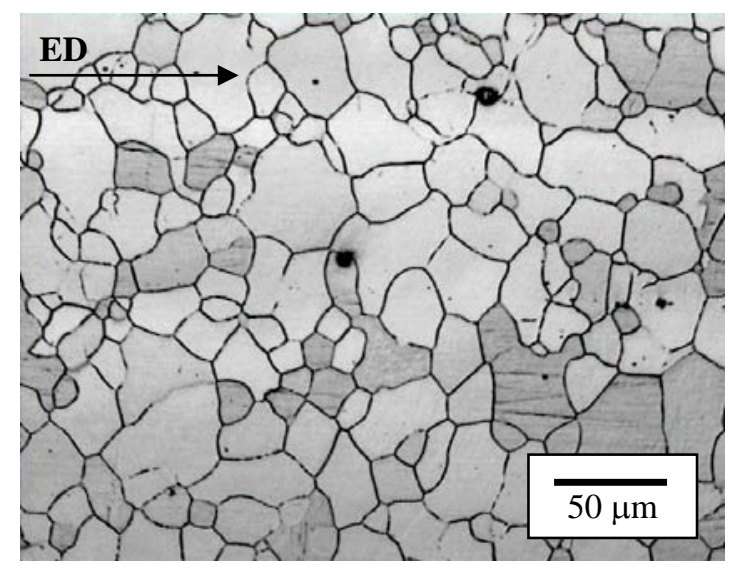

(b)

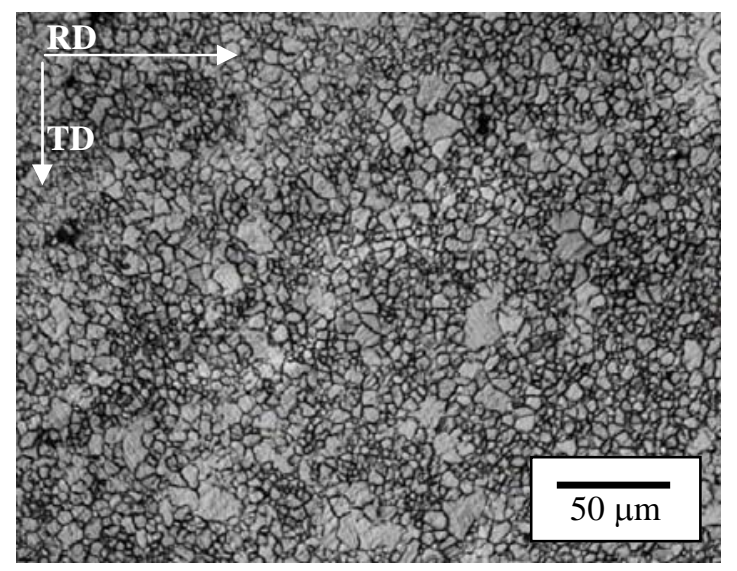

Figure 1. Optical micrographs showing the microstructure of the AZ61 alloy (a) in the as-received condition and (b) after large strain hot rolling at $375^{\circ} \mathrm{C}$ consisting on three passes with thickness reductions of $20 \%$, $35 \%$, and $55 \%$, respectively. $\mathrm{ED}=$ extrusion direction of the as-received material. $\mathrm{RD}=$ rolling direction. $\mathrm{TD}=$ transverse direction. 

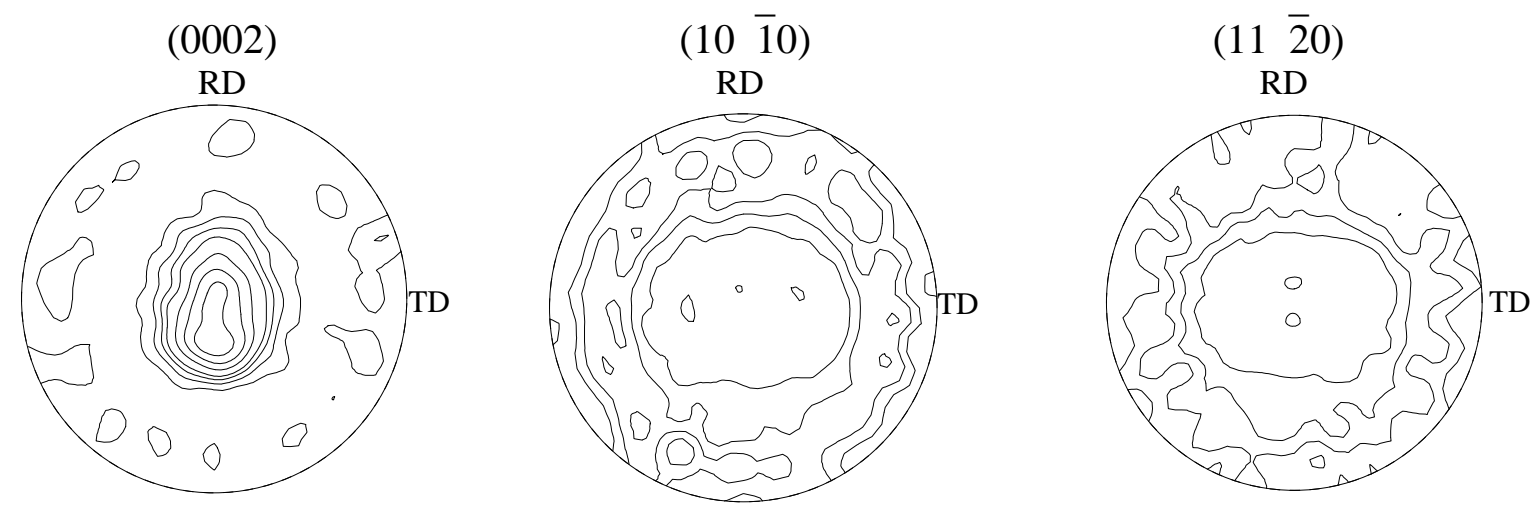

Figure 2. X-ray pole figures illustrating the macrotexture of the AZ61 alloy after large strain hot rolling. Intensity levels: 0.5,1,1.5,2,3,4,5.

In the following, the tensile response of the AZ61 Mg alloy processed by large strain hot rolling will be presented in order to explore the potential of this simple methodology to develop superplastic microstructures. Figure 3a depicts the true stress vs. true strain curves corresponding to tensile tests performed at $10^{-3} \mathrm{~s}^{-1}$ at temperatures ranging from $100^{\circ} \mathrm{C}$ to $400^{\circ} \mathrm{C}$. As expected, the flow stress decreases with increasing temperature. The elongations to failure achieved at each temperature are plotted in Fig. 3b. Maximum elongations of $400 \%$ are obtained at low to intermediate temperatures, namely at $250^{\circ} \mathrm{C}$ to $300^{\circ} \mathrm{C}$. Elongations as high as $700 \%$ were obtained when testing at $250^{\circ} \mathrm{C}$ and at a lower strain rate of $2 \times 10^{-4} \mathrm{~s}^{-1}$. However, significant scatter on the ductility data under these conditions was apparent. An example of a tensile specimen deformed up to $500 \%$ under the same conditions is shown in Fig. 5 . The scatter in the ductility data might be due to the effect of uncontrolled precipitation during the temperature stabilization and testing time. Mabuchi et al [4] also observed variations in ductility due to the different nature of the grain boundaries. They reported increasing elongations when equilibrium grain boundaries were present. Thus, for example, annealing after an ECAP processing of an AZ91 alloy was needed in order to improve the superplastic response. Further work is currently being carried out in order to elucidate the possible causes for the scatter in ductility in the present AZ61 alloy. Figure 6 illustrates the microstructure (Fig. 6a) and texture (Fig. 6b) of the sample deformed at $250^{\circ} \mathrm{C}$ and $2 \times 10^{-4} \mathrm{~s}^{-1}$ that reached an elongation of $700 \%$. Significant precipitation of the $\beta$-phase is apparent. Equiaxed grains of average size equal to $8.5 \mu \mathrm{m}$ can be observed. Additionally, a significant decrease in the texture intensity can be appreciated if Fig. 6b is compared with Fig. 2. These observations are consistent with the predominance of grain boundary sliding during deformation.

(a)

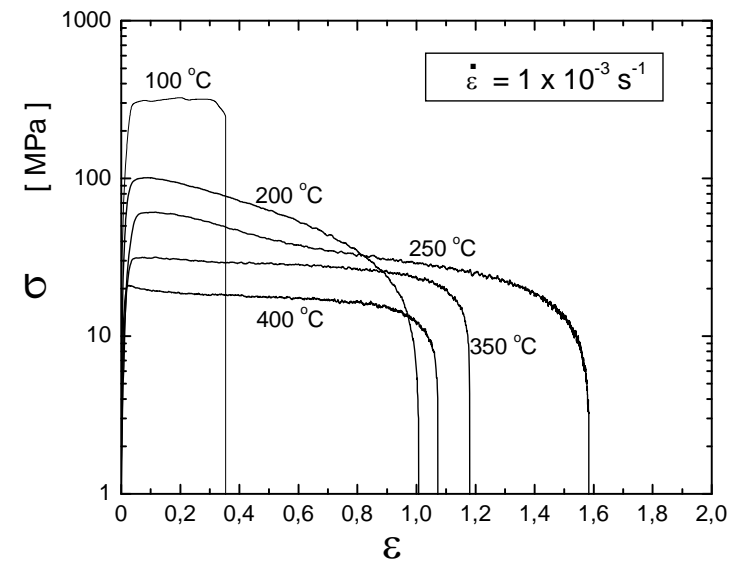

(b)

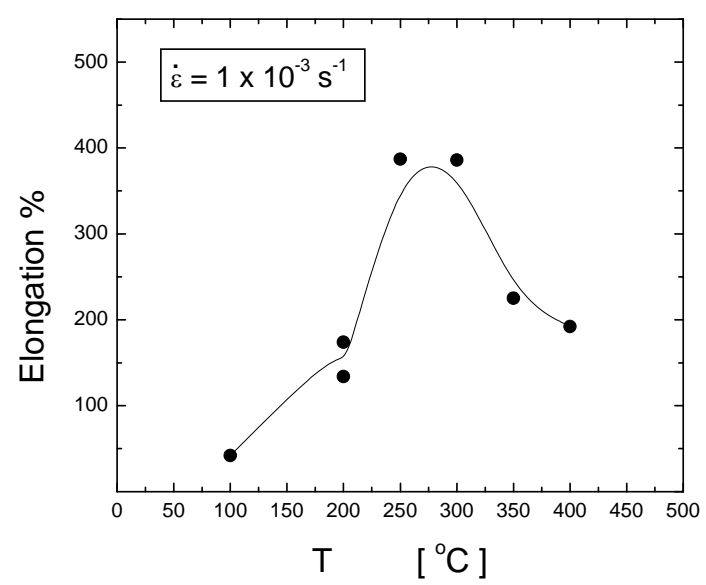

Figure 3. (a) Stress vs. strain curves corresponding to the AZ61 alloy (processed via large strain hot rolling) deformed uniaxially in tension at $10^{-3} \mathrm{~s}^{-1}$ and at temperatures ranging from $100^{\circ} \mathrm{C}$ to $400^{\circ} \mathrm{C}$. The tensile axis is the rolling direction. (b) Elongations to failure achieved in the tests of Fig. 3a. 


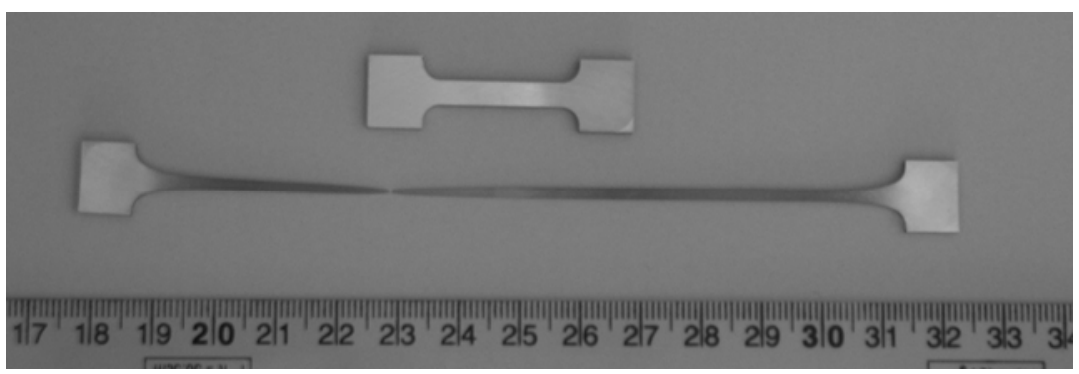

Figure 4. AZ61 tensile specimen tested at $250^{\circ} \mathrm{C}$ and $10^{-4} \mathrm{~s}^{-1}$.

(a)

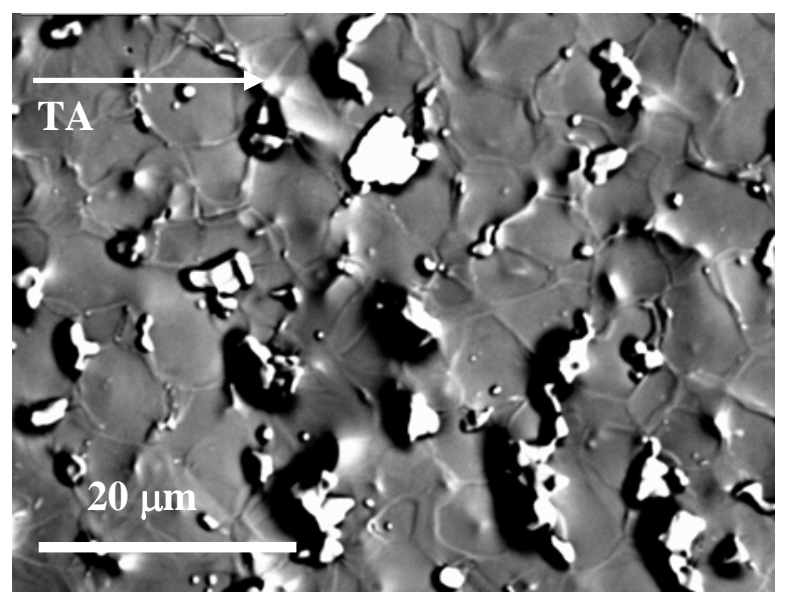

(b)

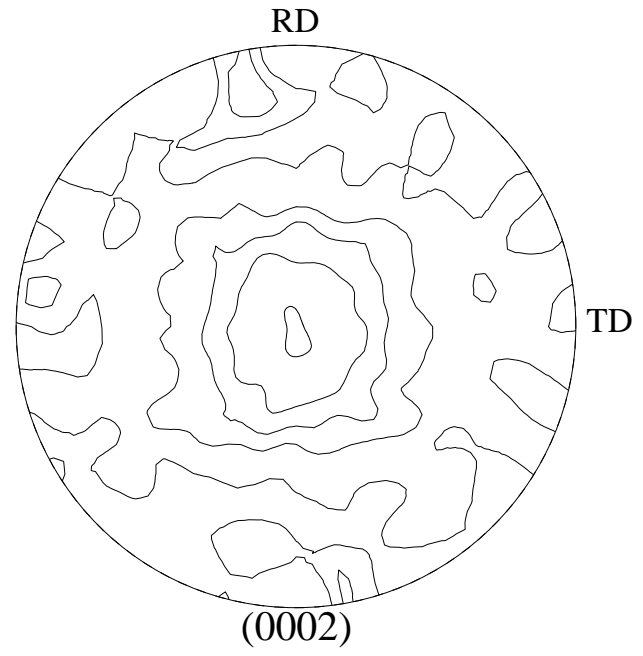

Figure 5. Microstructure of the AZ61 alloy processed via large strain hot rolling and then tensile tested at $250^{\circ} \mathrm{C}$ and $2 \times 10^{-4} \mathrm{~s}^{-1}$. The elongation to failure achieved was $700 \%$. The tensile axis (TA) is parallel to the rolling direction. (a) SEM micrograph (secondary electron mode) showing the grain structure and significant precipitation of the $\beta$-phase. (b) (0002) X-ray pole figure. Intensity levels: $0.5,1,1.5,2$.

Figure 6 illustrates the strain rate vs. stress plot corresponding to the AZ61 alloy processed via large strain hot rolling and subsequently tested at $250^{\circ} \mathrm{C}$ and $300^{\circ} \mathrm{C}$ at strain rates ranging from $2 \times 10^{-5} \mathrm{~s}^{-1}$ to $2 \times 10^{-2} \mathrm{~s}^{-1}$. At both temperatures two regimes can be clearly distinguished. At strain rates higher than about $10^{-3} \mathrm{~s}^{-1}$ at $300^{\circ} \mathrm{C}$ and $3 \times 10^{-4} \mathrm{~s}^{-1}$ at $250^{\circ} \mathrm{C}$ stress exponents equal to 4.4 are obtained. This suggests that dislocation slip is the main deformation mechanism under these conditions. At lower strain rates, however, stress exponents close to 1.7 are obtained, indicating the predominance of grain boundary sliding. It is to note that the maximum elongations are obtained under testing conditions that belong to the transition between both regimes. The activation energies measured in the dislocation slip and GBS-dominated regimes are, respectively, $121 \mathrm{~kJ} / \mathrm{mol}$ and 104 $\mathrm{kJ} / \mathrm{mol}$. These values are lower than those corresponding to diffusion of $\mathrm{Al}$ atoms in a $\mathrm{Mg}$ matrix (143 kJ/mole) and to self-diffusion in Mg (135 kJ/mole) [13] and they are higher than the activation energy for grain boundary diffusion $(92 \mathrm{~kJ} / \mathrm{mol})$. Kim et al. [14] have also reported a value of 121 $\mathrm{kJ} / \mathrm{mole}$ in an AZ31 alloy tested under conditions where a stress exponent of 3 was measured. Higashi [2] has recently pointed out that both lattice and grain boundary diffusion likely play an important role during superplastic deformation of $\mathrm{Mg}$ alloys and therefore an effective diffusion

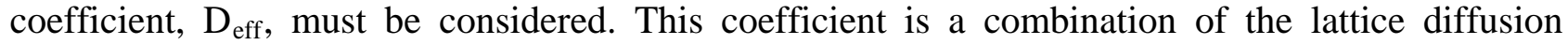
coefficient, $\mathrm{D}_{\mathrm{l}}$, and the grain boundary diffusion coefficient, $\mathrm{D}_{\mathrm{gb}}$. The exact contribution of each diffusion coefficient is, however, still not clearly established. 


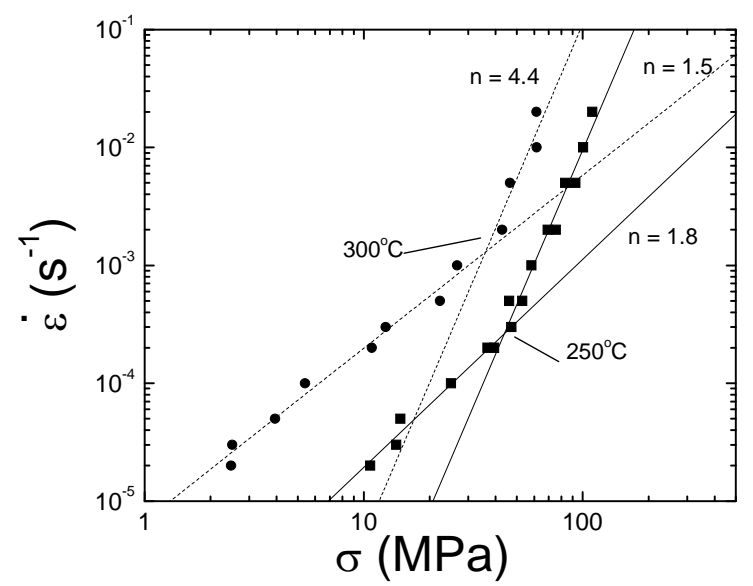

Figure 6. Strain rate vs. stress plot corresponding to the AZ61 alloy processed via large strain hot rolling. Data for this plot were obtained from strain rate change tests at $250^{\circ} \mathrm{C}$ and $300^{\circ} \mathrm{C}$, with strain rates varying from $2 \times 10^{-5} \mathrm{~s}^{-1}$ to $2 \times 10^{-2} \mathrm{~s}^{-1}$

\section{Conclusions}

The superplastic response of an AZ61 alloy processed via large strain hot rolling has been investigated. It has been shown that this simple grain refinement technique allows to develop microstructures that show significant superplastic elongations in the low temperature range and at moderate strain rates. Stress exponents equal to 2 are measured when testing within the superplastic regime, suggesting that grain boundary sliding is the predominant deformation mechanism. This is also evidenced by the presence of equiaxed grains after very large elongations as well as a significant decrease in the texture intensity during deformation. The activation energies obtained lie between the values corresponding to lattice self-diffusion and to grain boundary diffusion. This suggests that the rate-controlling mechanism might be a combination of both processes.

\section{Acknowledgements}

Financial support from a CICYT grant MAT2000-1313 is appreciated. MTP acknowledges a Ramón y Cajal 2001 contract, awarded by the Spanish Ministry of Science and Technology. JAV is thankful to CONICET for a postdoctoral grant.

\section{References}

[1] B. L. Mordike and T. Ebert: Mater. Sci. Eng. A, vol. 302 (2001), p. 37.

[2] K. Higashi: Proc. Iwasaki Workshop on Superplasticity, Ed. by H. Iwasaki, (Work-1 Co. Ltd, Sagamihara, Japan, 2003), p.89.

[3] T.G. Nieh, O.D. Sherby, and J. Wadsworth: Superplasticity in Metals and Alloys (Cambridge University Press, Cambridge, United Kingdom, 1997).

[4] M. Mabuchi, K. Ameyama, H. Iwasaki and K. Higashi: Acta Mater., vol. 47 (1999), p.2047.

[5] K. Kubota, M. Mabuchi, K. Higashi: J. Mater. Sci., vol. 34 (1999), p.2255.

[6] H.K. Lin and J.C. Huang: Mater. Trans., vol. 43 (2002), p.2424.

[7] Y.N. Wang, C.J. Lee, C.C. Huang, H.K. Lin, and J.C. Huang: Mater. Sci. Forum, vols. 426-432 (2003), p.2655.

[8] M. Mabuchi, T. Asahina, H. Iwasaki, K. Higashi: Mater. Sci. Tech. Vol. 13 (1997), p. 825. 
[9] R.Z. Valiev, R.K. Islamgaliev, I.V. Alexandrov: Prog. Mater. Sci., vol. 45(2) (2000), p. 103.

[10] J. A. del Valle, M. T. Pérez-Prado and O. A. Ruano: Mater. Sci. Eng. A, vol. 355 (2003), p. 68.

[11] M.T. Pérez-Prado, J.A. del Valle, J.M. Contreras, and O.A. Ruano: submitted to Scripta Materialia, 2003.

[12] V. Randle and O. Engler: Macrotexture, Microtexture and Orientation Mapping (Gordon and Breach Science Publishers, Amsterdam, The Netherlands, 2000).

[13] S.S. Vagarali and T.G. Langdon: Acta metal., vol. 30 (1982), p.1157.

[14] W.J. Kim, S.W. Chung, C.S. Chung, and D. Kum: Acta Mater., vol. 49 (2001) , p. 3337. 